\title{
A REPRODUÇÃO E O INÍCIO DA VIDA DE Hoplias malabaricus (Erythrinidae; Characiformes) NA AMAZÔNIA CENTRAL
}

\author{
Carlos A.R.M. ARAUJO-LIMA, Maria Mercedes BITTENCOURT
}

Resumo - Hoplias malabaricus, ou traíra é um peixe predador com ampla distribuição na América do Sul. É encontrado com freqüência na Amazônia, porém sua biologia ainda é pouco estudada na região. Nesta nota apresentamos dados relativos a sua reprodução e ao inicio do seu desenvolvimento larval na várzea do rio Solimões. A traíra se reproduz durante todo o ano. As fêmeas tem fecundidade relativamente baixa, que varia conforme o tamanho do peixe. Os ovócitos maduros são grandes (média $=1,5 \mathrm{~mm}$ ). Ovos fecundados foram encontrados em posturas nas margens dos lagos de várzea. As larvas eclodiram com $4,7 \mathrm{~cm}$ de comprimento e detalhes sobre seu desenvolvimento embrionário são apresentados.

Palavras-chave: peixe, reprodução, Hoplias, Amazônia, desenvolvimento larval

\section{Reproduction and Early Life History of Hoplias malabaricus in Central Amazon.}

Abtsract - Hoplias malabaricus is a predator fish widely distributed in South America. It is found frequently in the Amazon but its biology in the region is relatively unknown. We present here a description of its reproduction and early life history in a floodplain lakes of Rio Solimões. The fecundity of $H$. malabaricus is relatively low and increases with fish size. The mean diameter of ripe ovocytes are $1.5 \mathrm{~mm}$. Egg masses were found in the edges of the floodplain littoral. The larvae hatched with $4.7 \mathrm{~mm}$ of length and details of its larval development is here presented.

Key-words: Amazon, fish, Hoplias, reproduction, larval development

\section{Hoplias malabaricus (Boch} 1794) é uma espécie com ampla distribuição na América do Sul, sendo um dos principias predadores em reservatórios e riachos (Araujo-Lima, et al, 1995). É encontrada também em planícies inundadas e, embora não seja o piscívoro mais abundante neste ambiente, a sua ocorrência freqüente sugere ser uma espécie importante nestas comunidades. A reprodução da traira, nome pelo qual esta espécie é conhecida no Brasil, foi estudada nos rios e reservatórios de várias regiões do América do Sul, mas pouco se sabe sobre seu comportamento na Amazônia (Vazzoler e Menezes, 1992; Planquette et al, 1996). A espécie é conhecida como tendo desova parcelada e cuidado com a prole. $\mathrm{O}$ presente trabalho apresenta informações sobre a reprodução e o desenvolvimento larval inicial desta espécie na várzea do Rio Amazonas.

Durante o ano de 1987 realizamos 6 excursões de coleta, com freqüência bimestral, ao lago do Rei, situado na várzea do rio Amazonas, próximo a foz do rio Negro. Utilizamos redes de espera (malhadeiras) de tamanho variando entre 30 a $140 \mathrm{~mm}$ (entre nós opostos) colocadas nos principais habitats do lago, incluindo as moitas de capim e a floresta inundada.

Pesamos os peixes e

INPA, CPBA, C.X. 478, Manaus, Am, 69011-970; calima@inpa.gov.br 
examinamos suas gônadas para determinar o sexo e estádio de maturidade. De cinco fêmeas capturadas em janeiro-fevereiro (três individuos), abril e outubro (dois individuos), retiramos as gônadas, e as dissociamos em solução de Gilson para posterior contagem e determinação da fecundidade no laboratório. Os ovócitos foram contados em sub-amostras retiradas com uma pipeta Stempel.

Capturamos $99 \mathrm{H}$. malabaricus no lago Rei, sendo 34 fêmeas com gônadas em estágio final de maturação. As fêmeas maduras ocorreram em todos os meses de coleta. Foram, porém, menos abundantes em outubro, período da seca (Fig. 1a). A distribuição do tamanho dos ovócitos foi multimodal. As médias, desvios padrão e proporções de ovócitos dentro de cada moda foram separadas pelo programa MIX considerando um ajuste normal. Quatro fềmeas tinham de 4 a 5 modas de ovócitos imaturos e uma moda final de ovócitos maduros cuja diâmetro médio era $1,51 \mathrm{~mm}$ (desvio padrão= $0,07)$. Uma fêmea capturada em fevereiro não apresentava a moda com ovócitos maduros. O período de reprodução estendido ao longo do ano e a distribuição multimodal de ovócitos indica que esta espécie tem desova múltipla por temporada.

Determinamos o número de ovócitos das modas de maior diâmetro das 4 fêmeas baseado nas proporções ajustadas pelo programa MIX. O número de ovócitos nestas modas variou de 6446 na menor fêmea a
14131 na maior fêmea (Fig. 1b). A fecundidade parcial ("batch") ou o número de ovos liberados por desova era significativamente relacionado com o peso da fêmea $\left(r^{2}=0,92 ; N=4\right.$; $\mathrm{p}=0,03)$. A fecundidade anual pode atingir 5 vezes este valor se considerarmos o número de modas encontrada nos ovários, excluindo a primeira, que representa o estoque de ovócitos imaturos, e que representam os ovócitos liberados em um ano.

Esta espécie parece ser capaz de modular seu tipo de reprodução conforme o ambiente. Barbieri (1989) e Vazzoler e Menezes (1992) relataram um periodo longo de reprodução e desova parcelada no sul e sudoeste do Brasil. Machado-Allinson (1987) e Planquette et al (1996), por outro lado, registraram que o período de desova é curto com apenas um desova por temporada na época das chuvas nas savanas e rios do norte da América do Sul, mas longo e parcelado nos reservatórios da Venezuela. Planquette et al (1996) descreveram a fecundidade baseado no número de ovos das posturas. Estes autores encontraram nos rios da Guiana Francesa posturas com 2500 a 3000 ovos. A fecundidade parcial parece ser variável também entre os diversos estudos, mas os dados publicados não permitem uma análise estatistica.

Durante o início da enchente procuramos nas margens do lago ninhos de Hoplias como os encontrados em outras regiões (Moreira, 1919; Machado-Allinson, 1987). Localizamos apenas duas posturas em janeiro, das quais 
retiramos alguns ovos, que foram fixados em formalina a $4 \%$. Transportamos as posturas para o laboratório, onde as mantivemos em aquários com aeração constante para permitir o desenvolvimento do embrião e das larvas. A água dos aquários foi mantida a $29,5+\ldots \quad 0,5^{\circ} \mathrm{C}$, com renovação parcial diária $(50 \%)$ e ciclos de iluminação de $12 \mathrm{~h}$. Observamos o desenvolvimento dos embriões e larvas por 15 dias usando um estéreo microscópio. Após este período as larvas morreram, possivelmente por falta de alimentação adequada.

As duas posturas consistiam de uma massa de ovos arredondada de aproximadamente $5 \mathrm{~cm}$ de diâmetro. Elas foram encontradas em uma área rasa do fundo do lago próximo a vegetação. As posturas estavam a 15 $\mathrm{cm}$ de profundidade em ninhos em forma de pires feito no fundo. Nos dois casos, um peixe, presumivelmente uma traíra, se encontrava junto aos ovos, mas não pode ser identificado. As posturas eram formadas por ovos aderentes de cor amarela bem clara, que estavam na fase mórula e mediam $1,75 \mathrm{~mm}$ de diâmetro (desvio padrão $=0,04)$. Os ovos tinham um espaço perivitelínico
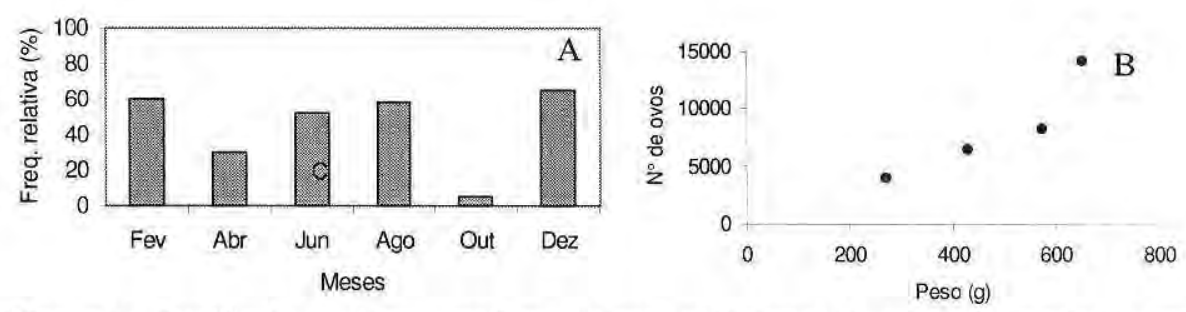

Figura 1. Freqüência de fêmeas maduras durante os 6 meses de coleta (a) e relação entre fecundidade parcial e peso total da fêmea (b). A equação de ajuste foi: fec= $1718,44 * \exp [0,003 *$ peso $]$ e $\mathrm{sb}=0,001$ 
aderidas ao fundo ou em grupos. Quatro dias após a eclosão mediam $5,9 \mathrm{~mm}$ (desvio padrão $=0,24)$, e estavam nadando no aquário, com a bexiga natatória inflada e se alimentando ativamente de micro-crustáceos. Os órgãos adesivos já não estavam ativos em metade dos indivíduos e o vitelo ainda era relativamente grande, sugerindo um crescimento lento para a larva desta espécie.

A postura da traíra na várzea é grande e parecem ficar expostas em um ninho aberto e com pouca vegetação circundante, especialmente em janeiro quando o nível da água está baixo. As margens do lago do Rei estão alteradas, mas não mais do que outros lagos de várzea do rio Amazonas, portanto esta situação não poderia ser considerada incomum para a traíra. Esta conspicuidade sugere pouca pressão de predadores. A proteção dos pais, associado a profundidade do local do ninho deve proteger eficientemente os ovos e larvas. As glândulas adesivas são possivelmente uma adaptação para evitar que as larvas se dispersem do ninho e reduzam a eficiência da proteção parental. Uma vez iniciado o período de alimentação exógena, as larvas teriam que se movimentar para encontrar alimento e as glândulas perdem então sua utilidade. O meio aquático da várzea que apresenta
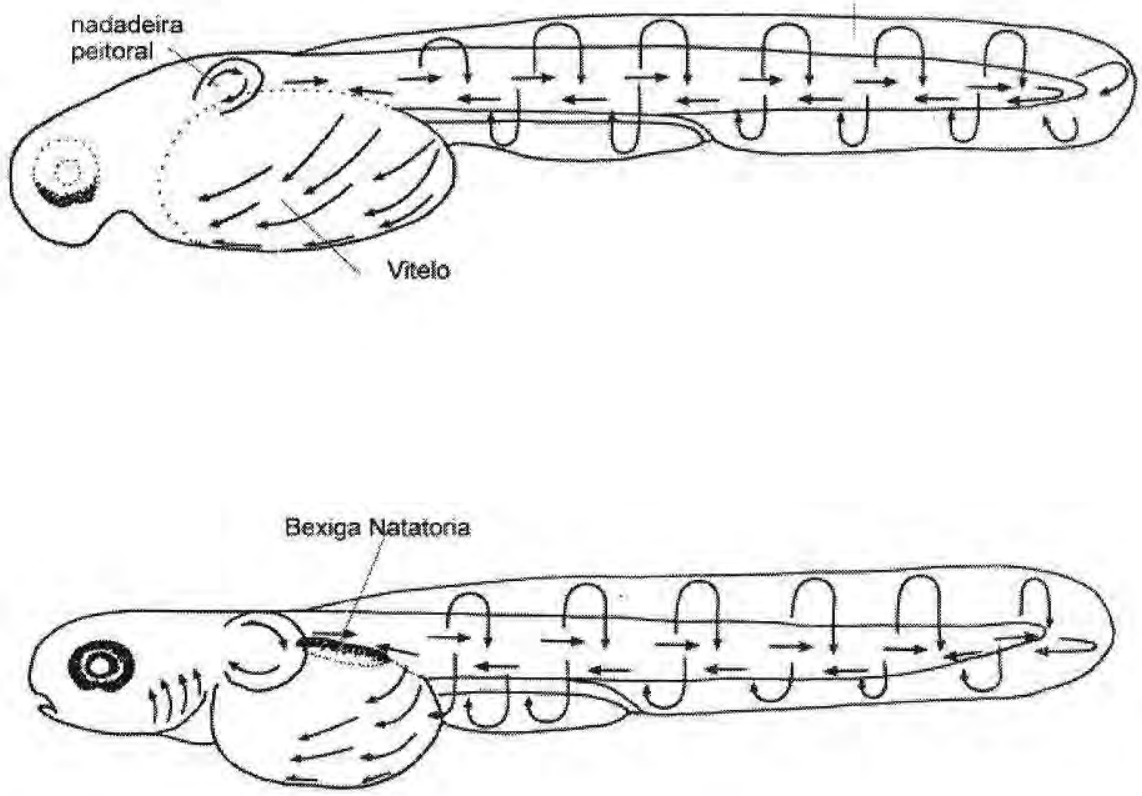

Figura 2. Larva de traíra recém eclodida com $5,2 \mathrm{~mm}$ de comprimento (acima) e no inicio da fase de alimentação exógena com $6,2 \mathrm{~mm}$ (abaixo) mostrando esquematicamente a direção da circulação sangüínea (setas). 
baixas concentração de oxigênio dissolvido deve exigir adaptações que otimizem a respiração. Esta deve ser a causa para que as larvas da traíra apresentem uma vascularização intensa sob a epiderme que deve aumentar a eficiência das trocas gasosas com o ambiente. Larvas de peixes que vivem no rio Amazonas, onde a concentração de oxigênio dissolvido é muito estável, apresentam pouca circulação sangüinea epidérmica (Araujo-Lima, 1985; Nascimento e Araujo-Lima, 1993).

\section{Bibliografia citada}

Araujo-Lima, C. A. R. M., 1985. Aspectos biológicos de peixes amazônicos. V. Desenvolvimento larval do jaraqui-escama grossa, Semaprochilodus insignis (Characiformes, Pisces) da Amazônia central, Revista Brasileira de Biologia 4 45: 423-431.

Araujo-Lima, C. A. R. M.; Agostinho, A. A.; Fabré, N. N., 1995. Trophic Aspects of Fish Communities in Brazilian Rivers and Reservoirs. In Tundisi J. G., Bicudo C. E. M. and Matsumura Tundisi T. (eds.), Limnology in Brazil. ABC/SBL. Rio de Janeiro, p. 105-136.

Barbieri, G., 1989. Dinâmica da reprodução e crescimento de Hoplias malabaricus (Bloch, 1794) (Osteichthyes, Erythrinidae) da represa do Monjolinho, São Carlos/SP. Revista Brasileira de Zoologia, 6: 225-233.

Machado-Allinson, A., 1987. Los peces de los llanos de Venezuela. Universidad Central de Venezuela, Caracas. 140 p.

Moreira, C., 1919. Recherches sur la reproduc- tion de Hoplias malabaricus (Bloch) et sur l'incubation d'oeufs de Salmo fario au Bresil. Bulletin Societe Zoologique de France 44: 329-336.

Nascimento, F.; Araujo-Lima, C. A. R. M., 1993. Descrição das larvas de Psectrogaster amazonica e Potamorhina altamazonica (Curimatidae, Pisces) da Amazônia Central. Acta Amazonica 23: 457-472.

Planquette, P.; Keith, P.; Le bail, P.Y., 1996. Atlas des poisson d'eau donce de Guyane (tome 1). Collection du Patrimoine Naturel, vol. 22. IEGB, MNHN, INRA, CSP, Min. Env. Paris. 429p

Vazzoler, A. E. A. M; Menezes, N. A., 1992. Síntese de conhecimentos sobre o comportamento reprodutivo dos Characiformes da América do Sul (Teleostei, Ostariophysi). Revista Brasileira de Biologia 52: 627-640. 